\title{
Development of Waste Heat Fired Activated Carbon Ammonia Adsorption Chiller
}

\author{
Mohammed Sadhikh $^{a}, *$, Jaice Joy Skaria ${ }^{b}$ \\ ${ }^{a}$ College of Engineering, King Khalid University, Abha, KSA \\ ${ }^{b}$ Mechanical Engineer, Engineering Innovation Design \& Consulting LLC, Oman
}

\begin{abstract}
Adsorption systems are promising alternative to the existing refrigeration systems in the wake of alarming energy crisis and potential danger due to the use of ozone depleting refrigerants. Sorption systems use thermal energy as its power source and solid adsorbent beds to adsorb and desorb a refrigerant to obtain the desired cooling effect. Solar energy, engine exhaust and low grade waste heat could be used to drive the sorption compressors. The use of non-ozone depleting refrigerant makes these systems environmentally benign. Adsorption refrigeration systems can meet the cooling requirement across a wide range of temperatures. These systems have minimal moving parts and hence they are free of noise, vibration and related problems. This paper will present the description, operation and simulated system characteristics for a $1000 \mathrm{~W}$ adsorption chiller. The adsorption system performance factors such as coefficient of performance (COP), specific cooling power (SCP), and cycle time were predicted. Parameters such as the generation and adsorption temperature, condenser and evaporator temperature were varied to analyze the influence of the varied operating conditions. A two bed $1000 \mathrm{~W}$ capacity adsorption water chiller to chill water from 12 to $7 \mathrm{C}$ was considered for the simulation. COP of the simulated system ranged between 0.3 to 0.4 and SCP from 90 to $180 \mathrm{~W} / \mathrm{kg}$ AC respectively. The maximum value of cycle time obtained was 25 minutes when the generation outlet temperature was $180^{\circ} \mathrm{C}$.
\end{abstract}

Keywords: Adsorption, Waste Heat, Chiller

\section{Introduction}

Adsorption refrigeration research has got enough attention during these years, as a good opportunity to replace $\mathrm{CFCs}$ or HCFCs in refrigeration, specially its potential applications in waste heat recovery, solar energy utilization etc. Adsorption cooling process utilizes the adsorbent adsorbate characteristics and produce cooling effect in the evaporator by the combination of adsorption-triggeredevaporation and desorption-resulted-condensation. Adsorption refrigeration system uses solid adsorbent beds to adsorb and desorb a refrigerant to obtain cooling effect. These solid adsorbent beds adsorb and desorb a refrigerant vapor in response to changes in the temperature of the adsorbent.

Adsorption systems have the benefits of energy saving as it is driven by waste heat or solar energy as well as no vibration and lower operation costs in comparison with mechanical vapor compression systems. However, vapor compression systems still dominate almost all application areas. This is because that there are certain disadvantages which make the commercialization of adsorption systems difficult. They are: (i) long adsorption/desorption time; (ii) small refrigeration

${ }^{*}$ Corresponding author

E-mail: msbasher@kku.edu.sa

(C) 2016 International Association for Sharing Knowledge and Sustainability

DOI: $10.5383 /$ ijtee. 11.02 .008 capacity per unit mass of adsorbent, i.e., low Specific Cooling Power (SCP), which leads to a bulky system; and (iii) low Coefficient of Performance (COP) of the system. It is preferred to have a very high COP value, high SCP value and low cycle time for vapor adsorption refrigeration systems. These inconveniences can be overcome by the intensification of heat and mass transfer properties in the adsorber, by increasing the adsorption properties of the working pairs and by a better heat management system. One such performance enhancement cycle known as vapor recovery cycle with pressure equalization is considered in this study. Vapor recovery helps to recover large amount of refrigerant trapped in the voids of the adsorbent particles.

\section{Adsorption Refrigeration System}

Adsorption refrigeration system uses solid adsorbent beds to adsorb and desorb a refrigerant to obtain cooling effect. These solid adsorbent beds adsorb and desorb a refrigerant vapor in response to changes in the temperature of the adsorbent. The basic adsorption refrigeration system or adsorption refrigeration circuit usually consists of the main components: solid adsorbent bed, condenser, expansion valve and an evaporator. In this study activated carbon ammonia pair is considered as the adsorbent-adsorbate pair. 
The solid adsorbent bed desorbs refrigerant when heated and adsorb refrigerant vapor when cooled. In this manner, the bed can be used as a thermal compressor to drive the refrigerant around the system to heat or cool a heat transfer fluid or to provide space heating or cooling. The refrigerant is desorbed from the bed as it is heated to drive the refrigerant out of the bed and the refrigerant vapor is conveyed to a condenser. In the condenser, the refrigerant vapor is cooled and condensed to liquid. The refrigerant condensate then expands to a lower pressure through an expansion valve and the low pressure condensate passes to an evaporator where the low pressure condensate takes the load and vaporizes.

When further heating of the bed no longer produces desorbed refrigerant, the bed is isolated and allowed to return to the adsorption conditions. When the adsorption conditions are established in the bed, the refrigerant vapor from the evaporator is reintroduced to the bed to complete the cycle. To obtain continuous and stable cooling effect in the operation of adsorption refrigeration system, generally two or more adsorbent beds are used in the system. In a typical two-bed cycle, one bed is heated during desorption period and the other bed is cooled during the adsorption period.

The time for the completion of a full cycle of adsorption and desorption is known as the "cycle time". The heating and cooling steps are reversed when the beds reach the desired upper and lower temperature limits of the adsorption cycle. The upper and lower temperatures will vary depending upon the selection of the refrigerant fluid and the adsorbent. The efficiency in cooling is called the "coefficient of performance" (COP) and is generally the ratio of the cooling effect divided by the heat input. Another efficiency indicator is named as "specific cooling power" (SCP) and is defined as the ratio between the cooling production and the cycle time per unit of adsorbent weight. The specific cooling power reflects the size of the system. For a nominal cooling load, higher SCP values indicate the compactness of the system.

\section{Adsorption Cycle Analysis}

Adsorbent in the generator/adsorber modules is heated during the generation phase and is cooled during the adsorption phase. Two sets of adsorption modules operating out of phase with each other ensure continuous production of cooling effect. Retention of ammonia in the vapor state, in the void volumes is significant at the end of the generation phase. COP of the basic adsorption cycle is enhanced using pressure equalization technique. In this technique the vapor spaces of the modules at the end of generation phase are communicated with the modules at the end of adsorption phase. This enables hot and high pressure ammonia vapor movement from the hot pressurized generating modules to the adsorbing modules. This leads to heat and mass recovery. The external heat required in the generator decreases and the cooling effect produced in the evaporator increases. This increases the cooling COP. The basic cycle is represented on the Pressure Temperature Concentration (P-T-x) diagram in Figure 1 and is divided into four phases.

Phase I - During this phase module set B is preheated from ph.i. to g.i. followed by the generation phase g.i. to g.o. Module set $\mathrm{A}$ is pre cooled from pc.i. to a.i. followed by the adsorption phase a.i. to a.o. During this phase module set B is heated by cartridge heater and module set A is cooled by water. Module set $\mathrm{B}$ is heated till it reaches the generation temperature and desorbs all the ammonia.
Phase II - During this phase pressure is equalized between module set A and B. Module set B is depressurized from g.o. to $\mathrm{pc} . \mathrm{i}$, its temperature and the concentration of the ammonia reduces. Module set A is pressurized from a.o to ph.i, temperature of module set A increases slightly and the concentration of ammonia in the adsorbent increases.

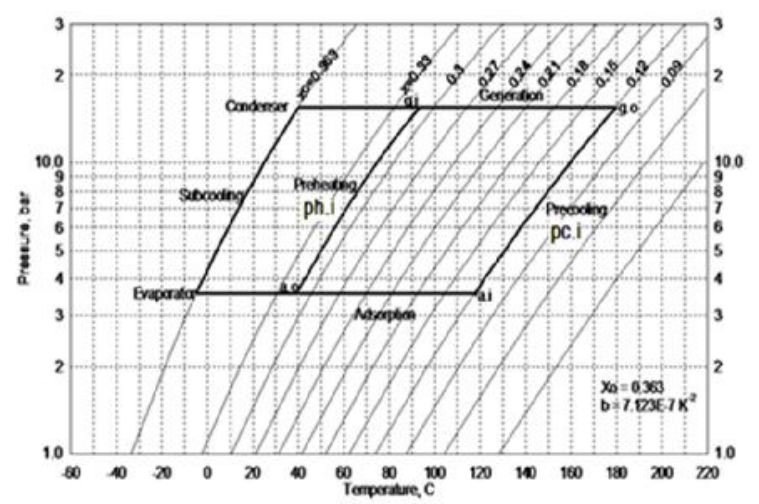

Figure 1 Cycle Processes Represented on P-T-x Diagram of Activated Carbon- Ammonia Pair

Phase III - The third phase is the reverse of the phase I wherein the module set $\mathrm{A}$ is now undergoing preheating and generation and module set $\mathrm{B}$ is now undergoing pre cooling and adsorption.

Phase IV - In this phase pressure equalization is again done between the two module sets followed by phase I

\section{Description of the System}

The activated carbon ammonia chiller is to produce chilled water between $12{ }^{\circ} \mathrm{C}$ and $7{ }^{\circ} \mathrm{C}$. An important requirement for the chilling of water is that the refrigerating effect should be continuous. The adsorption cycles are intermittent in nature. To obtain continuous cooling two modules are needed each working out of phase with each other. Each module is provided with condenser, a receiver and evaporator unit. The schematic of adsorption water chiller is shown in Figure 2. Engine exhaust was considered as the heat source for the adsorption chiller. To simulate the conditions in the laboratory model, it was proposed to use cartridge heaters. Separate cartridge heaters are inserted into each module. The module cooling is achieved by passing water through tubes brazed on the sides of the modules. Module A and module B are connected to the condensers and a reservoir is placed between each condenser and evaporator. The inlet and outlet of the evaporator coils are connected to the reservoirs. The evaporator region is insulated so that no heat transfer takes place with the surroundings. The cooling effect is obtained in the water container into which the evaporator coils are inserted. The proposed system is to chill the water in the evaporator container. Power supply to the heaters of each module is provided independently. While module A is on heating mode, Module B will be in cooling mode.

The continuous cooling is produced by switching the two modules in heating and cooling modes. When one module is switched from cooling to heating the other module is switched from heating to cooling. The thermal mass of the system should be minimum in order to reduce heating time. This will improve the performance of the system. For the vapor recovery between 
the modules the two beds are interconnected through a tube. This arrangement helps to recover a large amount of ammonia in the voids of the hot adsorbent bed. Also vapor recovery helps for pressure equalization in the modules. When the pressure equalization is done, the high pressure adsorbate from the hot bed goes to the cold bed, resulting in performance improvement. This vapor recovery results in energy saving, as part of the heat required for heating the adsorbent bed is supplied from the other. Thus the external heat input decreases and the COP of the system increases.

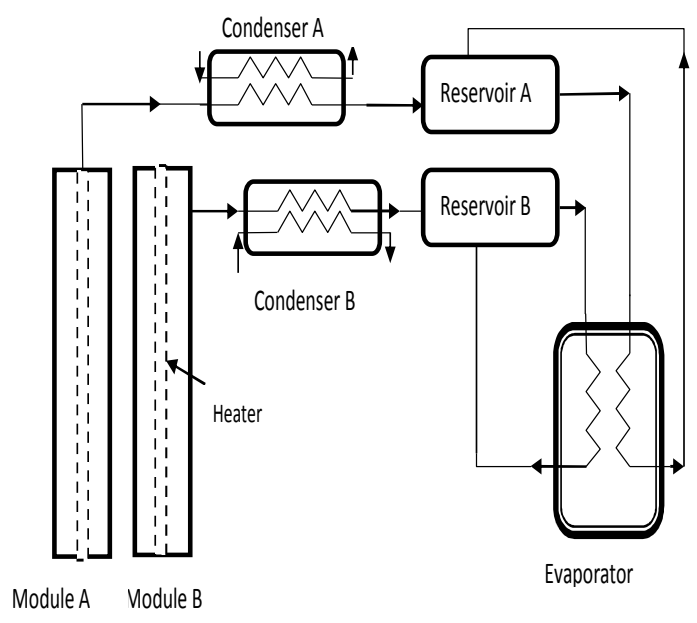

Figure 2 Schematic Diagram of Adsorption Chiller

\subsection{Working of the Chiller}

The adsorption water chiller is to produce chilled water. The system consists of two generator/adsorber modules, module set $\mathrm{A}$ and module set $\mathrm{B}$. Two modules are used in order to have continuous cooling. One set of modules will be in desorption phase while the other set of modules will be in adsorption phase. Both the modules are vertical and are insulated to prevent the heat loss to the surroundings and heat transfer with each other. The two condensers and reservoirs are placed in front of the two modules. The evaporator or the chilled water container is placed below. Heating of the module is achieved by cartridge heaters inserted in the module.

The electric supply to the heater is switched on. As the heating proceeds, ammonia adsorbed in activated carbon will be released. The ammonia vapors generated from the module passes into the condenser. The water supply to the condenser is also started as the heating of module A begins. After been condensed by the water, ammonia flows into the reservoir. The reservoir collects all the ammonia desorbed during heating and passes to the evaporator. Ammonia enters the evaporator tubes from the reservoir A. The water to be chilled is supplied to the evaporator. Evaporator is insulated to prevent heat leak from the surroundings. When all the ammonia gets released from the module A in heating mode, switching over of the module A to cooling mode and the module B to heating mode is done.

This is done manually by switching off the power supply to heater A and switching on the heater B. The cooling of the module $\mathrm{A}$ is done by passing water over the modules through the pipes integrated on the modules. Due to the temperature lowering effect of module A, activated carbon will become ready to adsorb ammonia. This cooling process will also lower the pressure in the system. The ammonia in the evaporator thus started vaporizing taking the load from the water in the chilled water tank and adsorbs back into module $\mathrm{A}$. This cycle is then repeated.

\subsection{Design Parameters}

The system has been designed for a cooling capacity, $\mathrm{q}_{\mathrm{eva}}$ of $1000 \mathrm{~W}$. The following data are used for the design of the components of the system.

$\begin{array}{ll}\text { Evaporator temperature, } \mathrm{T}_{\text {eva }}{ }^{\circ} \mathrm{C} & 4 \\ \text { Chilled water temperature, } \mathrm{T}_{\text {cw.e. }} / \mathrm{T}_{\text {cw.e.o }}{ }^{\circ} \mathrm{C} & 12 / 7 \\ \begin{array}{l}\text { Condenser temperature, } \mathrm{T}_{\text {con }}{ }^{\circ} \mathrm{C} \\ \text { Temperature of water in condenser, } \mathrm{T}_{\text {c.w. } .} / \mathrm{T}_{\text {c.w.o }}{ }^{\circ} \mathrm{C}\end{array} & 38 \\ \begin{array}{l}\text { Temperature of cartridge heater } \\ \text { used for heating modules, } \mathrm{T}_{\mathrm{ch}}{ }^{\circ} \mathrm{C}\end{array} & 30 / 35 \\ \begin{array}{l}\text { Temperature of cooling water } \\ \text { during adsorption, } \mathrm{T}_{\mathrm{m} . w .} / \mathrm{T}_{\mathrm{m} . w . o}{ }^{\circ} \mathrm{C}\end{array} & 325 \\ \begin{array}{l}\text { Temperature at the end of adsorption, } \mathrm{T}_{\text {a.o }}{ }^{\circ} \mathrm{C} \\ \text { Temperature at the end of generation, } \mathrm{T}_{\text {g.o }}{ }^{\circ} \mathrm{C}\end{array} & 40 / 38 \\ & 180 \\ \begin{array}{l}\text { The performance of the proposed system for various operating } \\ \text { conditions is predicted using a computer simulation program. }\end{array}\end{array}$

\section{Simulated Results and Discussion}

In the simulation of vapor adsorption chiller the quantities such as mass of the module, mass of activated carbon, mass of the refrigerant in the system during various processes are calculated. The effect of varying operating conditions such as generation outlet temperature, adsorption outlet temperature, condenser temperature and evaporator temperature on performance of the system is studied. This helps to find out the optimum working condition of the system. The heat loads during various processes in the cycle and performance parameters are calculated using the equations.

\subsection{COP, SCP vs. Generator Outlet Temperature}

In Figure.3, variation of COP with generator outlet temperature is plotted. The COP of the system decreased with increase in temperature. This is due to the fact that as the temperature is increased, more heat is required to heat the module. This increases the heating time for the modules. The heat input to the system increased whereas refrigerating effect remained the same. Figure 4 shows the variation of Specific Cooling Power (SCP) with generator outlet temperature, Tg.o. There is a linear increase in specific cooling power (SCP) with generation outlet temperature. The specific cooling power increases from 135 $\mathrm{W} / \mathrm{kg}$ to $175 \mathrm{~W} / \mathrm{kg}$ of activated carbon. This is due to larger concentration split at higher generation temperature. Thus the weight of activated carbon needed, size of the system reduces with increase in generator temperature. 


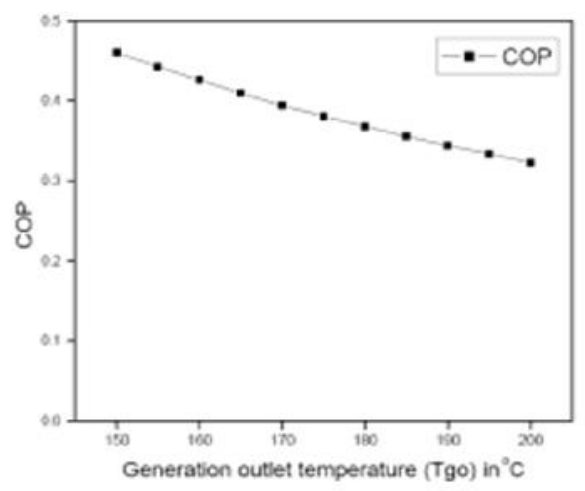

Figure 3 Variation of COP with Generation Outlet

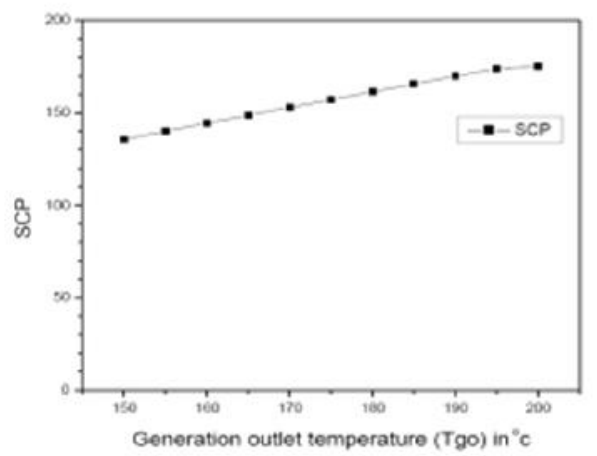

Figure 4 Variation of SCP with Generation Outlet

\subsection{COP, SCP vs. Cycle Time}

COP variation is shown in Figure 5. As the cycle time is increased, there is a rise in COP. Cycle time increases either when heating time of the module is increased or when adsorption time is increased. On increasing the heating time, the module is made to generate more refrigerant which helps to increase the refrigerating effect. As adsorption time is increased, more refrigerant vapor is allowed to adsorb by the modules. This helps to enhance the amount of heat transfer in the evaporator and increase the refrigerating effect. Thus increasing the time of both adsorption and desorption, the COP of the system increases.

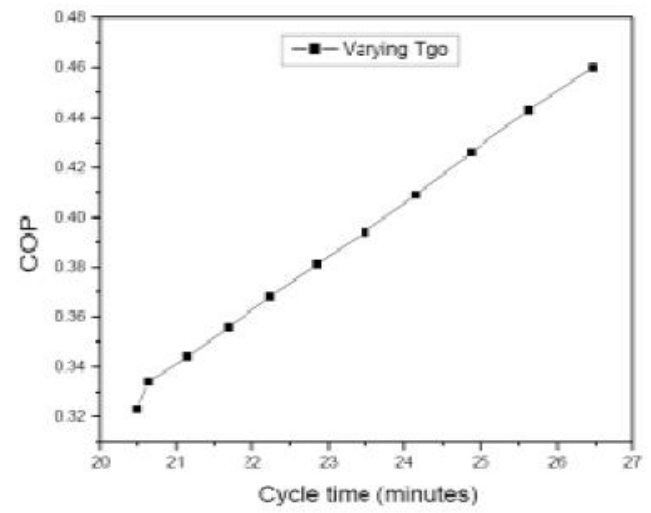

Figure 5 COP Vs. Cycle Time

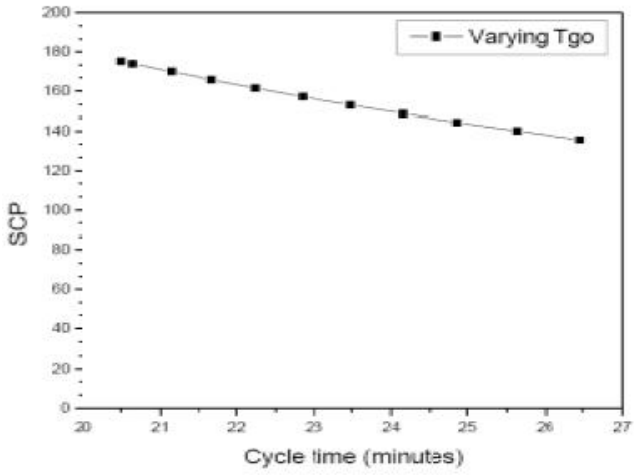

Figure 6 SCP Vs Cycle Time

Figure 6 shows variation of SCP with cycle time.SCP shows a decreasing trend with increase of cycle time. SCP is inversely related to cycle time. Even though refrigerating effect is increasing with cycle time, SCP was decreasing with time. The increased time for heating did not helped to increase the refrigerant amount beyond a certain limit. The increased heating was wasted by the sensible heating of module body and activated carbon as this does not help in refrigerating effect.

\subsection{COP, SCP vs. Evaporator Temperature}

Figure 7 and 8 shows the effect of variation of evaporator temperature on performance parameters $\mathrm{COP}$ and $\mathrm{SCP}$ of the system. COP increases from 0.32 to 0.38 with increase in temperature from $2{ }^{\circ} \mathrm{C}$ to $16{ }^{\circ} \mathrm{C}$. SCP also increased with increase in evaporator temperature. The generator heat load, weight of activated carbon, ammonia reduces as the evaporator temperature increase. This is due to increased concentration split and reduced preheating load at higher evaporator temperatures. Higher concentration split at higher evaporator temperature leads to increase in specific cooling power.

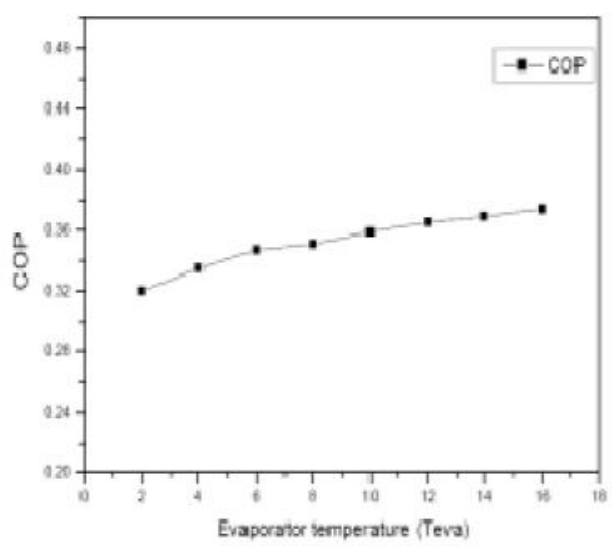

Figure 7 COP with Evaporator Temperature 


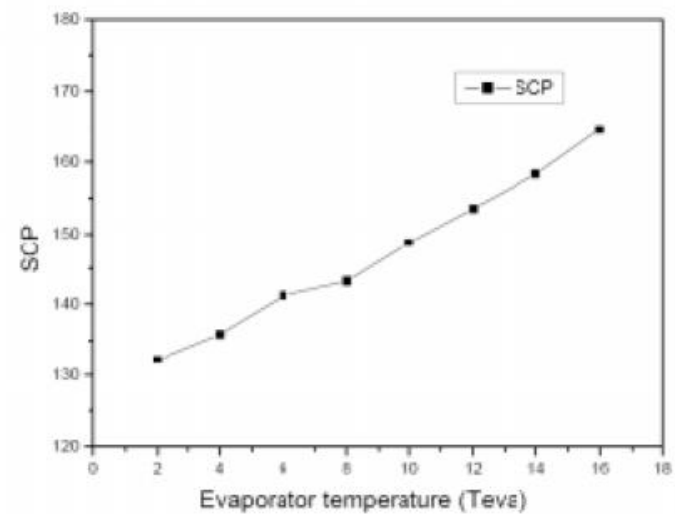

Figure 8 SCP with Evaporator Temperature

\section{Conclusion}

Activated carbon - ammonia adsorption chiller was developed. The simulation helped to study the system performance with varying operating conditions. The typical working conditions selected for study are the condenser temperature, evaporator temperature, and generator outlet temperature. The $\mathrm{COP}$ of the system varied between 0.3 and 0.45 . The maximum Specific Cooling Power and cycle time was $175 \mathrm{~W} / \mathrm{kg}$ when operated at generator outlet temperature of $200{ }^{\circ} \mathrm{C}$. The cycle time for the system was 25 minutes with a module diameter of $80 \mathrm{~mm}$ and length $850 \mathrm{~mm}$. The obtained simulated results show good agreement with the laboratory models in literature.

\section{Future Work}

The performance study obtained through simulation could be verified with experimental study on the developed system at the refrigeration laboratory. The simulation results can be revalidated with the experimental results as future work.

\section{References}

[1] Critoph, R.E., 1993, "Laboratory testing of an ammonia carbon solar refrigerator", paper presented at ISES, Solar World Congress, Budapest, Hungary, August 23-26,

[2] Dieng A. O. and Wang R. Z., 2001,'Literature review on solar adsorption technologies for ice-making and airconditioning purposes and recent developments in solar technology", Renewable and sustainable energy review, Vol 5(4), pp 313-342.

[3] Grenier, P.H., Guilleminot, J.J., Meunier, F., Pons, M., 1998, "Solar powered solid adsorption cold store", ASME J. Solar Energy Engg., Vol. 110 pp.192-197.
[4] Hisaki, H., Kobayashi, N., Yonezawa, Y., Morikawa, A., 1993, "Development of ice-thermal storage system using an adsorption chiller", paper presented at Int. Absorption Heat Transfer Conf, ASME-AES, Vol. Vol. 31 pp.43944.

[5] Jiangzhou S., Wang R.Z., Lu Y.Z., Xu Y.X., Wu J.Y. and Li Z.H., 2003, "Locomotive driver cabin adsorption airconditioner", Renewable Energy, Vol. 28, pp 1659-1670.

[6] Liu, Y.L., Wang, R.Z., Xia, Z.Z., 2005, "Experimental performance of a silica gel-water adsorption chiller", Applied Thermal Engineering, Vol 25, pp 359-375

[7] Meunier, F, "A solar-powered ice-maker with the solid adsorption pair of activated carbon and methanol", International journal of energy research,1999, Vol. 23(6),pp $517-527$

[8] Michel Pons (1997), "Principle of adsorption cycle for refrigeration or heat pumping", CNRS/LIMSI

[9] Milind V Rane, Mohammed Sadikh, Solomon T.T., 2007, "Waste heat fired shipboard chilling system", International Congress of Refrigeration 2007, Beijing

[10] Miles, D.J., Shelton, S.V., 1996, "Design and testing of a solid sorption heat pump system", Appl. Thermal Engineering, Vol. 16 pp.389-94.

[11] Sadik Kakac, Hongton Liu, Heat exchangers-Selection, Rating and Thermal Design, CRC press, London

[12] Saha, B.B., Boleman, E.C., Kashiwagi, T., 1995,"Experimental investigation of silica gel-water adsorption refrigeration cycle - the influence of operating conditions on cooling output and COP", ASHRAE Trans., Vol. 101 pp.425-31.

[13] Tiansuwan, J., Hirunlabh, J., 1998, “Mathematical model of an activated carbon ethanol refrigerator", Thammasat

International Journal of Science and Technology, Vol. 3, pp 66-71

[14] Wang, R. Z. and Oliveira, R.G., 2005, “Adsorption refrigeration - an efficient way to make use of waste heat and solar energy", International sorption heat pump conference, Denver, USA, June 22-24,2005

[15] Wang, R. Z., 2000, "Adsorption refrigeration research in Shanghai Jiao Tong University", Renewable and Sustainable energy reviews, Vol 5, pp 1-37

[16] Wang S.G. and Wang R.Z. 2005, "Recent developments of refrigeration technology in fishing vessels", Renewable Energy, Vol. 30, pp 589-600

[17] Yong, L and Wang, R. Z., 2007, “Adsorption refrigeration: a survey of novel technologies, Recent patents on engineering", Vol 1, pp 1-21 